\title{
The Impact of Coronavirus COVID-19 Pandemic on Food Purchasing, Eating Behavior, and Perception of Food Safety in Kuwait
}

\author{
Dana AlTarrah ${ }^{1, *(\mathbb{C})}$, Entisar AlShami ${ }^{2}$, Nawal AlHamad ${ }^{2}$, Fatemah AlBesher ${ }^{2}$ and Sriraman Devarajan ${ }^{3}$ (I) \\ 1 Faculty of Public Health, Kuwait University, Kuwait City 12037, Kuwait \\ 2 Public Authority for Food and Nutrition, Kuwait City 207, Kuwait; eashami1@hotmail.com (E.A.); \\ n.alhamad@pafn.gov.kw (N.A.); fnalbesher@hotmail.com (F.A.) \\ 3 Dasman Diabetes Institute, Kuwait City 15462, Kuwait; sriraman.devarajan@dasmaninstitute.org \\ * Correspondence: danah.altarrah@ku.edu.kw
}

check for updates

Citation: AlTarrah, D.; AlShami, E.; AlHamad, N.; AlBesher, F.; Devarajan, $\mathrm{S}$. The Impact of Coronavirus COVID-19 Pandemic on Food Purchasing, Eating Behavior, and Perception of Food Safety in Kuwait. Sustainability 2021, 13, 8987. https:// doi.org/10.3390/su13168987

Academic Editors: George Saridakis and Nikolaos Dadios

Received: 29 June 2021

Accepted: 3 August 2021

Published: 11 August 2021

Publisher's Note: MDPI stays neutral with regard to jurisdictional claims in published maps and institutional affiliations.

Copyright: (c) 2021 by the authors. Licensee MDPI, Basel, Switzerland. This article is an open access article distributed under the terms and conditions of the Creative Commons Attribution (CC BY) license (https:/ / creativecommons.org/licenses/by/ $4.0 /)$.

\begin{abstract}
During the COVID-19 pandemic, the government in Kuwait implemented public health measures to control the spread of the virus. However, despite the importance of these restrictions, normal activities related to purchasing of groceries, concerns related to food safety, and overall uncertainty may have influenced food behaviors and food consumption. Hence, the study investigates the impact of COVID-19 on food purchasing behaviors, eating behaviors, and the perception of food safety and security among residents in Kuwait. A cross-sectional study was carried out using self-administered questionnaires between 28 July 2020 and 31 August 2020 during the COVID-19 pandemic in Kuwait. A total of 841 respondents participated in the study. The study identified several changes in food purchasing behaviors, eating behaviors, food consumption, and consumers perceptions on food safety during the pandemic. The closures, restrictions, and changes in food purchasing evidently influenced individual's eating behaviors. Largely, participants were found to (i) change their food purchasing behavior (74\%); (ii) opt for online food delivery services (42.8\%); (iii) purchase long-shelf-life foods (e.g., canned food and dry staples) (76\%); (iv) consume more meals at home (76\%); and (v) follow public health measures to reduce the spread of the virus and ensure their safety (98\%). This study indicates that individuals during times of uncertainty and stress change their food purchasing behaviors, food consumption habits, and follow guidelines and recommendations. These findings may help public health initiatives to focus on raising awareness about the importance of health, wellbeing, and nutrition during times of crises.
\end{abstract}

Keywords: food purchasing; food safety; eating behavior; COVID-19; pandemic; Kuwait; perception

\section{Introduction}

The novel coronavirus disease-19 (COVID-19) is caused by severe acute respiratory syndrome coronavirus 2 (SARS-CoV-2) [1]. Due to its high transmissibility, following its identification late December 2019 in Wuhan, China, the disease spread rapidly worldwide to more than 200 countries [1,2]. Consequently, by 11 March 2020 the World Health Organization (WHO) declared COVID-19 as a pandemic [3].

The disease was found to adversely affect the respiratory system. However, although the majority of associated symptoms were reported to be mild, certain sub-groups of the population, including elderly, obese, and/or those with underlying medical conditions (e.g., type 2 diabetes, cardiovascular diseases, hypertension), were at higher risk of severe illness and fatality $[4,5]$. In line with the WHO recommendations, governmental bodies worldwide implemented measures to stop and control the fast spread of the disease. These measures focused primarily on implementing procedures to promote handwashing, social distancing, and use of face masks. Likewise, health promotion campaigns focused on highlighting the importance of encouraging a healthy lifestyle through a balanced diet and physical activity [6]. 
In Kuwait, the government implemented measures to reduce the spread of the disease and lessen the burden on the health care system. Similar to many other countries, Kuwait adhered to the WHO recommendations to maintain the food supply, food safety, and nutritional status of the population [7]. By 12 March 2020, the Kuwaiti government announced nationwide closures of all business, including both governmental and private agencies, educational institutions (schools and universities), hospitality services, and food outlets. On 22 March 2020, the Kuwaiti government imposed a partial lockdown followed by a total lockdown which included the suspension of all aviation except for cargo until 30 June 2020 to prevent social gatherings and preserve the health of citizens and residents in Kuwait [8]. During this period, online food delivery services, take-away services, and supermarkets remained open, and the nation was assured that the food supply chain will remain fully functional, and that food stocks were abundant and widely accessible. In aims to prevent panic-buying and stock-piling daily necessities (e.g., toilet paper, canned food, dry staples, hand sanitizers, and drinking water), as observed in some countries [9-11], the Ministry of Commerce and Industry (MOCI) in Kuwait imposed strategic regulations and guidance [9,12], which were similar to those implemented in New Zealand, Australia, the USA, and the UK $[12,13]$. The electronic booking system implemented by MOCI permitted one adult from each household access to supermarkets or food stores once a week for a shopping duration of $30 \mathrm{~min}$. In addition to public health measures such as mask wearing, social distancing at least $2 \mathrm{~m}$, and hand washing or using hand sanitizers, these changes were effective in managing the number of shoppers at each visit, and controlling panicbuying, which would consequently reduce the spread of COVID-19. However, despite the importance of imposing these measures to control the spread of the virus in Kuwait, the extent and magnitude of COVID-19 in Kuwait on food purchasing, eating behaviors, and food safety was unknown, as such no previous study was published at the time in Kuwait and neighboring Arab Gulf countries. Hence, the present study aimed to investigate the impact of the pandemic on the food purchasing behaviors, eating behaviors, and overall perception of food safety in Kuwait. The next section provides a literature review, which is followed by a presentation of the results and finally the discussion and conclusions.

\section{Literature Review: Impact of COVID-19 on Food Purchasing, Eating Behaviors and Food Safety}

The COVID-19 pandemic affected all aspects of everyday life, which in turn influenced food purchasing, food consumption, eating behaviors, and perceptions on food safety $[14,15]$. Several recent studies have elucidated that disruptions to the food supply chains, food export/import restrictions, limitations within food markets, inflation of food prices, and limited accessibility to supermarkets due to restrictions have influenced attitudes and behaviors related to food purchasing and consumption [16-18]. These disruptions collectively affected food purchasing and eating behaviors, and due to the increased concern of contracting COVID-19, food safety measures received greater attention. With respect to food supply, many countries reported delays in harvests due to employees self-isolating, under curfews or lockdowns [19]. Moreover, disturbances to the food supply chain and accessibility to food markets increased wastage of perishable foods such as fruits and vegetables $[20,21]$. In aims of preventing food shortages that may occur if international food suppliers limit the export of goods, local food production was encouraged to ensure sustainable access to food during the pandemic [22,23].

Following the WHO declaring COVID-19 as a pandemic [3], food purchasing behaviors and eating behaviors changed. Several studies and news outlets documented that consumers began panic-buying and stockpiling food staples (e.g., rice, pasta, canned foods, legumes, pulses, and frozen foods) to avoid future food shortages as uncertainty rose worldwide [9,24-26]. Several studies reported that changes in purchasing behaviors were a result of consumers fear of not having enough food, and less of concerns of food shortages [25]. Another reason for consumers to stockpile and/or panic-buy was postulated to be related to consumers' cautiousness to reduce their risk of contracting the virus during their food shop [27]. Others described these changes in purchasing behavior as an innate 
human response to crises and stress, and thus consumers stockpiled to feel safe and in control $[25,26,28]$.

The COVID-19 pandemic was also found to influence food consumption and eating behaviors, which either improved or deteriorated the health status of individuals [29]. Closures of schools, lockdowns, working from home, and living in confinement have been reported to increase food consumption of convenience foods (snacks, chocolate bars, crisps) and processed foods (frozen meals and frozen breaded meats) which in turn adversely affected overall diet quality [30]. The growing fear and psychological impact of COVID-19 pandemic was documented during the pandemic [31-34]. One study in China reported an increase in the level of anxiety, depression, and stress, which in turn may have increased the risk of emotional overeating or undereating [31-34]. Similarly, other studies observed that stress, fear, and self-isolation during quarantine increased the consumption of comfort foods (e.g., ice creams, confectionaries, and chocolate, etc.) and led to weight gain [35-37]. For instance, one study in Italy found that, due to excessive stress and anxiety, 19.5\% reported weight gain, $42.5 \%$ reported an increase in the consumption of energy dense foods (e.g., deserts, confectionaries, pastries etc.), and 23.5\% reported an increase in their intake of savory snacks (e.g., fried foods, crisps, and crackers etc.) [35]. These dietary changes were also reported in another study in Italy, where Di Renzo et al. [36] found that respondents reported a greater appetite and increased food consumption during quarantine and lockdowns [36].

Conversely, the pandemic was reported to have a positive impact on food purchasing behaviors and eating behaviors. For instance, one study in Tunisia found that the restrictions and lockdowns led to a reduction in food waste [38]. In Italy, Di Renzo et al. [36] found that over half of the respondents (54\%) reported using leftovers more than a third of the time [36]. Moreover, due to the closures of restaurants and cafes, many had to prepare home-cooked meals, bake bread, and make desserts. For example, a large survey in the US on grocery shopper trends reported that Americans were found to cook more (41\%), meal plan $(27 \%)$, and try new meals and recipes $(20 \%)$. These changes collectively may positively influence eating behaviors and encourage healthier dietary habits [39]. In Qatar, Ben Hassen et al. [40] also found that individuals were consuming more meals prepared at home, and many enjoyed trying new recipes which may explain the shift towards healthier dietary habits observed in their study [40].

Similarly, individuals' perceptions on food safety were found to shift during the COVID- 19 pandemic, which in turn influenced purchasing and eating behaviors. Due to the growing concern on the safety of food, particularly animal products, several studies reported a decrease in the consumption of meat [41] and an increase in home cooking to avoid restaurant food deliveries [38-40]. Others reported that consumers opted for online grocery delivery services to reduce their risk of infection, and chose to eat more locally, due to their concerns about the safety of imported food products [40].

\section{Materials and Methods}

\subsection{Study Design and Participants}

A cross-sectional study was conducted between 28 July and 31 August 2020 to investigate the impact of the COVID-19 pandemic on food purchasing habits, dietary consumption, food safety, and security perception among adults in Kuwait. The target population, which included all adults aged over 18 years residing in Kuwait during the COVID-19 pandemic, were invited to participate in a web-based online survey. The snowball sampling method was used. Participants were asked to complete the questionnaire and share with their contacts, in order to recruit a large majority of the population and ensure wide distribution of the survey.

A web-based online survey tool (Google Forms, version 2020) was used. Online surveys were considered the safest and most effective method to ensure social distancing measures are followed. WhatsApp (version 2.21.15.19) a widely used communication platform, was used to disseminate the survey. Following a brief message that explained 
the study aims and objectives, participants were invited to participate. Participation was voluntary and confidential after obtaining consent. A total of 841 participants were included in the current study.

\subsection{Questionnaire}

Data was collected using a self-administered questionnaire developed by researchers at the Public Authority of Food and Nutrition (PAFN) in Kuwait. The questionnaire items were adapted from the International Food Information Council following the attainment of permission [42]. The questionnaire was translated into the Arabic language, and culturally tailored following internationally accepted criteria. The questionnaire was disseminated in the Arabic to suit the majority of the Arabic-speaking population living in Kuwait [43,44]. Pilot study was carried out on 20 participants to examine the clarity and acceptability of the questionnaire. Simple modifications were made following pilot-testing the questionnaire. The questionnaire included 19 questions, which were categorized into five sections.

Section 1 on sociodemographic background included four questions on gender, nationality (Kuwaiti, non-Kuwaiti), age category (18-25 years, 26-41 years, 41-65 years, $>65$ years), and area of residence known as governorates (Capital, Hawalli, Farwania, Mubarak Al Kabeer, Al Ahmadi, and AJahra). Section 2 included four questions that focused on whether they changed their food purchasing behaviors during the COVID-19 pandemic; how their food purchasing habits changed (e.g., shopped more, shopped less, purchased canned food); their main worries while shopping (e.g., fear of infection, not enough food or money); and the type of foods they ensured having at home. Section 3 included four questions that focused on perceptions of food safety, security, and hygienic practices. Participants were asked about their perceptions and trust of the safety of food purchased from supermarkets and restaurants; their perceptions and trust of the food delivery services (Likert scale: I trust - I do not trust at all); the steps they took to ensure their safety while shopping; and the steps they wished food handlers would take to ensure the safety of shoppers. Section 4 included six questions that focused on whether food consumption behaviors changed during the COVID-19 pandemic (increased, decreased, stayed the same); reasons for increase or decrease in food consumption; how they believe their food consumption behavior changed (e.g., eating more food prepared at home, eating more food that usual etc.); the type of food they ate more of; and the type of beverage they had more of. Section 5 included one question that focused on participants perception of food security; participants were asked on how confident they were in the country's' ability to supply enough food for all after their experience during the COVID-19 pandemic (Likert scale: highly confident, somewhat confident, not confident, not confident at all).

\subsection{Ethical Approval}

All participants gave their informed consent for inclusion before they participated in the study. The study was conducted in accordance with the Declaration of Helsinki, and the protocol was approved by the Ethics Committee Board of the Ministry of Health, Kuwait.

\subsection{Statistical Analysis}

Statistical analysis was performed using IBM SPSS Statistics version 25 (Armonk, NY, USA. Descriptive analysis was carried out to calculate frequencies and percentages for categorical variables. Bar charts were used to display descriptive data. Statistical significance was determined using the chi-squared $\chi^{2}$ test and Fisher's exacts test as applicable. A probability value $p<0.05$ was considered as statistically significant.

\section{Results}

\subsection{Sociodemographic Characteristics}

A total of 841 respondents participated in the study, of which $77.9 \%$ were females, and $83.8 \%$ were Kuwaiti. The majority were aged between $41-65$ years old $(51.2 \%)$ and 
$45.1 \%$ resided in the capital governorate (area of residence). Table 1 presents the sociodemographic characteristics of study participants.

Table 1. Sociodemographic characteristics of study participants.

\begin{tabular}{|c|c|}
\hline & $\begin{array}{c}\text { All }(n=841) \\
n(\%)\end{array}$ \\
\hline \multicolumn{2}{|l|}{ Gender } \\
\hline Male & $186(22.1)$ \\
\hline Female & 655 (77.9) \\
\hline \multicolumn{2}{|l|}{ Age Category } \\
\hline $18-25$ years & $52(6.2)$ \\
\hline 26-40 years & $303(36)$ \\
\hline $41-65$ years & $431(51.2)$ \\
\hline Older than 65 years & $55(6.5)$ \\
\hline \multicolumn{2}{|l|}{ Nationality } \\
\hline Non-Kuwaiti & $136(16.2)$ \\
\hline Kuwaiti & $705(83.8)$ \\
\hline \multicolumn{2}{|l|}{ Governorate } \\
\hline Capital & $380(45.2)$ \\
\hline Hawalli & $278(33.1)$ \\
\hline Farwania & $42(5.0)$ \\
\hline Mubarak Al Kabeer & $75(8.9)$ \\
\hline AlAhmadi & $46(5.5)$ \\
\hline AlJahra & $20(2.4)$ \\
\hline
\end{tabular}

\subsection{Food Purchasing Behaviors}

Food purchasing behavior of all study participants are displayed in Supplementary Figures S1-1 to S1-3. A total of 73\% reported that they changed their food purchasing behavior, of which $16 \%$ shopped more than usual, whilst $44 \%$ shopped less than usual. Around a third preferred shopping online, $25.6 \%$ spent less time while shopping, and $27.6 \%$ purchased more food (in quantity) each time participants shopped. Participants purchased more dry food (e.g., beans, rice, lentils, legumes) and frozen food (e.g., ready meals, vegetables, etc.), and less canned food (12.2\%). The majority of participants had a fear of getting infected while shopping $(71.2 \%)$, and $45.2 \%$ indicated that they worry about the difficulty in reaching the supermarkets, whereas only $5 \%$ reported that they worried about having enough money, and $11.5 \%$ were not worried at all. When asked about the type of food they ensured having at home, $75.6 \%$ and $68.8 \%$ reported dry food and fresh produce, respectively, and only $15.5 \%$ indicated that they ensured having candy and savory snacks at home. Food purchasing behavior according to gender and nationality are presented in Table 2.

\subsubsection{Gender Comparison}

Several food purchasing behaviors were found to be statistically different between genders. Females were found to shop less $(45.8 \%$ vs. $37.6 \% ; p=0.047)$ and purchase more food items each time they shopped $(24.4 \%$ vs. $21.5 \% ; p=0.032)$. Whereas, males purchased more canned food $(17.2 \%$ vs. $10.8 \% ; p=0.024)$ and worried that there was not enough food supply $(35.5 \%$ vs. $25.8 \% ; p=0.011)$. When asked what type of food they ensured to have available at home, purchasing of candy and savory snacks ( $14.0 \%$ vs. $21.0 \% ; p=0.011)$, and 
canned food ( $35.0 \%$ vs. $48.0 \% ; p=0.024)$ were statistically greater among males compared to females, whereas purchasing ready-made frozen food $(24.7 \%$ vs. $32.1 \%$; $p=0.052)$ was statistically greater among females compared to males.

Table 2. Food purchasing behaviors according to gender and nationality.

\begin{tabular}{|c|c|c|c|c|}
\hline & \multicolumn{2}{|c|}{$\begin{array}{l}\text { Gender } \\
n(\%)\end{array}$} & \multicolumn{2}{|c|}{$\begin{array}{l}\text { Nationality } \\
n(\%)\end{array}$} \\
\hline & Male & Female & Non-Kuwaiti & Kuwaiti \\
\hline $\begin{array}{c}\text { Food purchasing habits } \\
\text { changed }\end{array}$ & $137(73.7)$ & $486(74.2)$ & $112(82.4)^{*}$ & $511(72.5)$ \\
\hline \multicolumn{5}{|l|}{$\begin{array}{l}\text { How did food purchase } \\
\text { change? }\end{array}$} \\
\hline Shop more & $39(21.0)$ & $101(15.4)$ & $12(8.8)$ & $128(18.2)$ * \\
\hline Shop less & $70(37.6)$ & $300(45.8) *$ & $73(53.7) *$ & $297(42.1)$ \\
\hline Shorter shopping duration & $42(22.6)$ & $173(26.4)$ & $50(36.8)^{*}$ & $165(23.4)$ \\
\hline Prefer online shopping & $47(25.0)$ & $213(32.5)$ & $27(19.9)$ & $233(33.0) *$ \\
\hline $\begin{array}{l}\text { Purchase more food each time } \\
\text { I shop }\end{array}$ & $40(21.5)$ & $160(24.4) * *$ & $39(28.7) * *$ & $161(22.8)$ \\
\hline Purchase dry food more & $63(32.3)$ & $169(25.8)$ & $56(41.2)$ & $176(25.0)$ \\
\hline Purchase frozen food more & $60(32.0)$ & $183(28.0)$ & $37(27.2)$ & $206(29.2)$ \\
\hline Purchase canned food more & $32(17.2)^{*}$ & $71(10.8)$ & $20(14.7)$ & $83(11.8)$ \\
\hline Purchase fresh food less & $30(16.1)$ & $109(16.6)$ & $23(16.9)$ & $116(16.6)$ \\
\hline \multicolumn{5}{|l|}{ Worry while purchasing food } \\
\hline Fear of infection & $128(68.8)$ & $471(71.9)$ & $106(77.9)$ & $493(69.9)$ \\
\hline Not enough food & $66(35.5) *$ & $169(25.8)$ & $37(27.2)$ & $198(28.1)$ \\
\hline Not enough money & $9(4.8)$ & $33(5.0)$ & $24(17.6)^{* *}$ & $18(2.6)$ \\
\hline $\begin{array}{c}\text { Difficulty reaching } \\
\text { supermarket }\end{array}$ & $85(45.7)$ & $295(45.0)$ & $56(41.2)$ & $324(46.0)$ \\
\hline No worries & $24(12.9)$ & $73(11.1)$ & $10(7.4)$ & $87(12.3)$ \\
\hline \multicolumn{5}{|l|}{$\begin{array}{c}\text { Type of food you ensured } \\
\text { having at home }\end{array}$} \\
\hline $\begin{array}{c}\text { Dry food (rice, oats and } \\
\text { lentils) }\end{array}$ & $147(79.0)$ & $489(74.7)$ & $111(81.6)$ & $525(74.5)$ \\
\hline Fresh produce (dairy, fruits) & $119(64.0)$ & $458(69.9)$ & $93(68.4)$ & $484(68.7)$ \\
\hline Candy and savory snacks & $39(21.0) *$ & 91(13.9) & $15(11.0)$ & 115 (16.3) \\
\hline Ready-made frozen food & $46(24.7)$ & $210(32.1) *$ & $9(6.6)$ & $247(35.9)^{* *}$ \\
\hline $\begin{array}{l}\text { Canned food (tuna, fava } \\
\text { beans, chickpeas) }\end{array}$ & $89(48.0) *$ & $230(35.1)$ & $62(45.6) *$ & $257(36.5)$ \\
\hline
\end{tabular}

\subsubsection{Nationality Comparison}

There were several differences in food purchasing behaviors between Kuwaiti and nonKuwaiti respondents. During the COVID-19 pandemic, 82.4\% non-Kuwaitis were found to change their food purchasing behavior compared to $72.5 \%$ Kuwaitis $(p=0.013)$. Kuwaitis were found to shop more ( $18 \%$ vs. $8.8 ; p=0.004)$, whilst non-Kuwaitis were found to shop less $(53.7 \%$ vs. $42.1 \% ; p=0.013)$. Preference for online shopping was statistically different; $33.0 \%$ of Kuwaitis compared to $19.9 \%(p=0.002)$ were found to prefer online shopping. Whereas, non-Kuwaitis were found to purchase more food items each time $(p<0.001)$ and spend a shorter duration at the grocery store while shopping $(p=0.002)$. Concerns and 
uncertainties during shopping were statistically different between the nationalities with respect to worrying about a lack of money, as non-Kuwaitis worried more about their financial capacities $(17.6 \%$ vs. $2.6 \% ; p<0.001)$ compared to Kuwaitis.

\subsection{Food Safety}

Food safety perceptions of all study participants are displayed in Supplementary Figures S2-1 to S2-4. Approximately $85 \%$ of the study participants reported that they 'trusted' or 'somewhat trusted' the safety of food purchased from supermarkets; however, around $60 \%$ of participants did 'not trust' or 'did not trust at all' food purchased from restaurants/food delivery services. With respect to steps taken during shopping to feel safe, the majority of participants actively took steps to ensure their safety was maintained during shopping; $87.5 \%$ washed their hands after shopping, 70.3\% opted to use credit cards instead of cash, $58.6 \%$ used sanitizers, over half $(60.4 \%)$ avoided busy times, $64.2 \%$ visited less often, and $42.8 \%$ used online food services. Only $2.5 \%$ reported that no precautions or steps were taken. Food safety perceptions and measures taken by respondents, according to gender and nationality, are presented in Table 3.

Table 3. Food safety according to gender and nationality.

\begin{tabular}{|c|c|c|c|c|}
\hline & \multicolumn{2}{|c|}{$\begin{array}{c}\text { Gender } \\
n(\%)\end{array}$} & \multicolumn{2}{|c|}{$\begin{array}{c}\text { Nationality } \\
n(\%)\end{array}$} \\
\hline & Male & Female & Non-Kuwaiti & Kuwaiti \\
\hline \multicolumn{5}{|l|}{ Supermarket food safety } \\
\hline Yes, I trust the food I purchase & $80(43.0)$ & $348(53.1) *$ & $62(45.6)$ & $366(51.9)$ \\
\hline Yes, I somewhat trust the food I purchase & $70(37.6)$ & $224(34.2)$ & $53(39.0)$ & $241(34.2)$ \\
\hline No, I don't trust the food I purchase & $20(10.8) *$ & $38(5.8)$ & $11(8.1)$ & $47(6.7)$ \\
\hline No, not at all I don't trust the food I purchase & $6(3.2) *$ & $6(0.9)$ & $1(0.7)$ & $11(1.6)$ \\
\hline \multicolumn{5}{|l|}{ Restaurant and food delivery safety } \\
\hline Yes, I trust the food I purchase & $24(12.9) *$ & $45(6.9)$ & $12(8.8)$ & $57(8.1)$ \\
\hline Yes, I somewhat trust the food I purchase & $45(24.2)$ & $150(22.9)$ & $27(19.9)$ & $168(23.8)$ \\
\hline No, I don't trust the food I purchase & $59(31.7)$ & $220(33.6)$ & $39(28.7)$ & $240(34.0)$ \\
\hline No, not at all I don't trust the food I purchase & $44(23.7)$ & $191(29.2)$ & $46(33.8)$ & $189(26.8)$ \\
\hline \multicolumn{5}{|l|}{ Steps taken during shopping to feel safe } \\
\hline Shop online & $75(40.3)$ & $285(43.5)$ & $30(22.1)$ & $330(46.8)^{* *}$ \\
\hline Visit the grocery store less often & $111(59.7)$ & $429(65.5)$ & $92(67.6)$ & $448(63.5)$ \\
\hline Shop during less busy periods & $115(61.8)$ & $393(60.0)$ & $88(64.7)$ & $420(59.6)$ \\
\hline $\begin{array}{c}\text { Avoid touching surfaces/products while I } \\
\text { shop }\end{array}$ & $83(44.6)$ & $327(49.9)$ & $80(58.8) *$ & $330(46.8)$ \\
\hline Use sanitizers and wipes while I shop & $89(47.8)$ & $404(61.7) * *$ & $78(57.4)$ & $415(58.9)$ \\
\hline Purchase more frozen and canned food & $34(18.3)$ & $92(14.0)$ & $23(16.9)$ & $103(14.6)$ \\
\hline Purchase less fresh food & $18(9.7)$ & $52(7.9)$ & $11(8.1)$ & $59(8.4)$ \\
\hline Pay using my card instead of cash & $117(62.9)$ & $474(72.4) *$ & $85(62.5)$ & $506(71.8) *$ \\
\hline Leave my purchases for $2 \mathrm{~h}$ once $\mathrm{I}$ am home & $17(9.1)$ & $107(16.3) *$ & $17(12.5)$ & $107(15.2)$ \\
\hline Clean my purchases when I arrive home & $96(51.6)$ & $371(56.6)$ & $73(53.7)$ & $394(55.9)$ \\
\hline Wash my hands after shopping & $155(83.3)$ & $581(88.7)$ & $121(89.0)$ & $615(87.2)$ \\
\hline Dispose of the shopping bags and packaging & $90(48.4)$ & $366(55.9)$ & $89(65.4)^{*}$ & $367(52.1)$ \\
\hline No change & $7(3.8)$ & $14(2.1)$ & $2(1.5)$ & $19(2.7)$ \\
\hline \multicolumn{5}{|l|}{$\begin{array}{c}\text { Steps that should be taken by staff and food } \\
\text { handlers }\end{array}$} \\
\hline Wash surfaces that regularly touched & $140(75.3)$ & $498(76.0)$ & $101(74.3)$ & $537(76.2)$ \\
\hline Providing wipes and sanitizers & $92(49.5)$ & $348(53.1)$ & $72(52.9)$ & $368(52.2)$ \\
\hline Wearing gloves and masks during work & $153(82.3)$ & $555(84.7)$ & $111(81.6)$ & $597(84.7)$ \\
\hline Cleaning food containers regularly & $74(39.8)$ & $324(49.5) *$ & $62(45.6)$ & $336(47.7)$ \\
\hline $\begin{array}{l}\text { Ensure staff follow social distancing } \\
\text { measuring }\end{array}$ & $116(62.4)$ & $458(69.9)$ & $87(64.0)$ & $487(69.1)$ \\
\hline
\end{tabular}




\subsubsection{Gender Comparison}

Females were found to trust the safety of the food purchased at supermarkets compared to males ( $53 \%$ vs. $43 \% ; p=0.015)$. While, more males were found to trust food purchased from restaurants/delivery food services $(13 \%$ vs. $7 \% ; p=0.012)$. Statistically significant differences were also found for the steps taken to ensure food safety while shopping. More females compared to males were found to be cautious by using hand sanitizers and wipes $(p=0.001)$, paying using a credit card $(p=0.014)$, and shared that they wished food handlers would regularly clean food containers $(49.5 \%$ vs. $40 \% ; p=0.019)$.

\subsubsection{Nationality Comparison}

Steps taken to ensure food safety while shopping for food, such as using online shopping and credit cards instead of cash, were significantly greater among Kuwaiti compared to non-Kuwaiti $(46.8 \%$ vs. $22.1 \% ; p<0.001$ and $71.8 \%$ vs. $62.5 \% ; p=0.033$, respectively). Other precautions, such as an avoidance of touching surfaces during shopping $(58.8 \%$ vs. $46.8 \% ; p=0.010)$ and a disposal of bags and packaging $(65.4 \%$ vs. $52.1 \%$; $p=0.004)$, were significantly higher among non-Kuwaiti compared to Kuwaiti respondents.

\subsection{Food Consumption}

Food consumption of all study participants are displayed in Supplementary Figures S3-1 to S3-6. Almost half of the study participants indicated that their food consumption habits stayed the same (44\%). Of those that reported an increase $(33.7 \%)$ or decrease (18.4\%) in food consumption, the main reason for both changes were due to the lockdown ( $27 \%$ and $9.9 \%$, respectively). Sedentary behaviors, such as watching TV and using electronics, were also indicated as a reason for the increase in food consumption, and $7.5 \%$ reported more food to be the reason. Anxiousness and fear were reported to increase $(9.6 \%)$ and decrease $(6.5 \%)$ food consumption. The large majority $(86.8 \%)$ indicated that they ate more meals prepared at home, $67.8 \%$ ate less from restaurants and $39.4 \%$ ate more 'healthy' food than usual. As such, 50.3\% reported that they ate more of fruits and vegetables, legumes and pulses (41.5\%), and less fast food (2.3\%). Water was the most common type of beverage consumed (69.7\%), followed by coffee and tea (57.6\%). Around $40 \%$ of participants reported no change in the type of food they consumed. Food consumption and eating habits according to gender and nationality are presented in Table 4.

\subsubsection{Gender Comparison}

Food consumption habits were found to be statistically different between genders. More males reported that they consumed less food $(23.7 \%$ vs. $16.9 \% ; p=0.042)$, and the main reason found for the decrease in food consumption among males compared to females was due to less food available at home $(p=0.005)$.

Differences were also found for changes in eating habits. Females were found to eat healthy food more than usual, $(41.5 \%$ vs. $31.7 \% ; p=0.015)$, whereas more males reported to consume more 'rice-based dishes' $(48.4 \%$ vs. $31.3 \% ; p<0.001)$, and coffee and tea $(66.1 \%$ vs. $55.1 \% ; p=0.007)$.

\subsubsection{Nationality Comparison}

No differences were found between Kuwaiti and non-Kuwaiti respondents with respect to change in food consumption behaviors. However, significant differences were found for reasons why food consumption decreased where $9.6 \%$ of non-Kuwaiti reported less money.

Kuwaitis (88\%) ate more food prepared at home compared to $78 \%$ of non-Kuwaitis $(p<0.005)$. Conversely, $77.9 \%$ of non-Kuwaitis ate less food from restaurants compared to $65.8 \%$ of Kuwaitis $(p=0.004)$.

The types of foods and beverages consumed more by participants were found to be significantly greater for the consumption of baked goods and pastries ( $44 \%$ vs. $30.1 \%$; $p=0.002)$ and juices (30.1\% vs. $22.0 \% ; p=0.044)$ among Kuwaitis. 
Table 4. Food consumption according to gender and nationality.

\begin{tabular}{|c|c|c|c|c|}
\hline & \multicolumn{2}{|c|}{$\begin{array}{c}\text { Gender } \\
n(\%)\end{array}$} & \multicolumn{2}{|c|}{$\begin{array}{c}\text { Nationality } \\
n(\%)\end{array}$} \\
\hline & Male & Female & Non-Kuwaiti & Kuwaiti \\
\hline \multicolumn{5}{|l|}{ Did your food consumption habits change? } \\
\hline Food consumption increased & $65(34.9)$ & $218(33.3)$ & $39(28.7)$ & $244(34.6)$ \\
\hline Food consumption decreased & $44(23.7) *$ & 111(16.9) & $26(19.1)$ & $129(18.3)$ \\
\hline Food consumption stayed the same & $71(38.2)$ & $297(45.3)$ & $66(48.5)$ & $302(42.8)$ \\
\hline \multicolumn{5}{|l|}{ Reason for increase in food consumption } \\
\hline Anxiousness/fear & $22(11.8)$ & $59(9.0)$ & $13(9.6)$ & $68(9.6)$ \\
\hline Lockdown (partial/full) & $50(26.9)$ & $177(27.0)$ & $32(23.5)$ & $195(27.7)$ \\
\hline Watching TV/electronics & $23(12.4)$ & $99(15.1)$ & $16(11.8)$ & $106(15.0)$ \\
\hline More food at home & $14(7.5)$ & $49(7.5)$ & $9(6.6)$ & $54(7.7)$ \\
\hline \multicolumn{5}{|l|}{ Reason for decrease in food consumption } \\
\hline Anxiousness/fear & $9(4.8)$ & $46(7.0)$ & $13(9.6)$ & $42(6.0)$ \\
\hline Lockdown (partial/full) & $19(10.2)$ & $64(9.8)$ & $12(8.8)$ & $71(10.1)$ \\
\hline Less money available & $2(1.1)$ & $14(2.1)$ & $13(9.6) * *$ & $3(0.4)$ \\
\hline Less food at home & $9(4.8) *$ & $8(1.2)$ & - & $17(2.4)$ \\
\hline \multicolumn{5}{|l|}{ How did your food consumption change? } \\
\hline I eat more food prepared at home & $154(82.8)$ & $574(87.6)$ & $107(78.7)$ & $621(88.1) *$ \\
\hline I eat less food from restaurants & $125(67.2)$ & $445(67.9)$ & $106(77.9) *$ & $464(65.8)$ \\
\hline I eat less food than usual & $21(11.3)$ & $107(16.3)$ & $19(14.0)$ & $109(15.5)$ \\
\hline I eat more food than usual & $27(14.5)$ & $74(11.3)$ & $12(8.8)$ & $89(12.6)$ \\
\hline I eat healthy food more than usual & $59(31.7)$ & $272(41.5)$ * & $57(41.9)$ & $274(38.9)$ \\
\hline I eat healthy food less than usual & $10(5.4)$ & $31(4.7)$ & $8(5.9)$ & $33(4.7)$ \\
\hline Eating habits did not change & $25(13.4)$ & $100(15.3)$ & $20(14.7)$ & $105(14.9)$ \\
\hline \multicolumn{5}{|l|}{ What type of food did you eat more of? } \\
\hline Dairy products (milk and cheese) & $83(44.6)$ & $280(42.7)$ & $53(39.0)$ & $310(44.0)$ \\
\hline Baked goods and pastries & $85(45.7)$ & $266(40.6)$ & $41(30.1)$ & $310(44.0) *$ \\
\hline Pasta & $59(31.7)$ & $173(26.4)$ & $31(22.8)$ & $201(28.5)$ \\
\hline Rice & $90(48.4)^{* *}$ & $205(31.3)$ & $47(34.6)$ & $248(35.2)$ \\
\hline Fruits and vegetables & $101(54.3)$ & $322(49.0)$ & $72(52.9)$ & $351(49.8)$ \\
\hline Legumes and pulses & $88(47.3)$ & $261(39.8)$ & $61(44.9)$ & $288(40.9)$ \\
\hline Meat, poultry and eggs & $59(31.7)$ & $150(22.9)$ & $32(23.5)$ & $177(25.1)$ \\
\hline Fish and seafood & $50(26.9)$ & $148(22.6)$ & $36(26.5)$ & $162(23.0)$ \\
\hline Desserts and savory snacks & $33(17.7)$ & $150(22.9)$ & $24(17.6)$ & $159(22.6)$ \\
\hline Fast food & $2(1.1)$ & $17(2.6)$ & $2(1.5)$ & $17(2.4)$ \\
\hline No change & $31(16.7)$ & $167(25.5)$ & $37(27.2)$ & $161(22.8)$ \\
\hline \multicolumn{5}{|l|}{ What type of beverages did you have more of? } \\
\hline Water & $145(78.0)$ & $441(67.3)$ & $89(65.4)$ & $497(70.5)$ \\
\hline Energy drinks & $4(2.2)$ & $15(2.3)$ & - & $19(2.7)$ \\
\hline Juices & $54(29.0)$ & $142(21.7)$ & $41(30.1) *$ & $155(22.0)$ \\
\hline Artificially flavored drinks & $15(8.1)$ & $12(1.8)$ & $3(2.2)$ & $24(3.4)$ \\
\hline Coffee and tea & $123(66.1)$ * & $361(55.1)$ & $73(53.7)$ & $411(58.3)$ \\
\hline Carbonated drinks and soda & $16(8.6)$ & $79(12.1)$ & $11(8.1)$ & $84(11.9)$ \\
\hline No change & $28(15.1)$ & $147(22.4)$ & $33(24.4)$ & $142(20.1)$ \\
\hline
\end{tabular}

Data presented as number (percentage); Significance: ${ }^{* *} p<0.001,{ }^{*} p<0.05$.

\subsection{Perception of Food Security}

The large majority of study participants were confident in the country's ability to provide food to meet consumer needs; $57.2 \%$ and $34.5 \%$ were highly confident and somewhat confident, respectively, while $4.2 \%$ were not confident (Figure 1). 


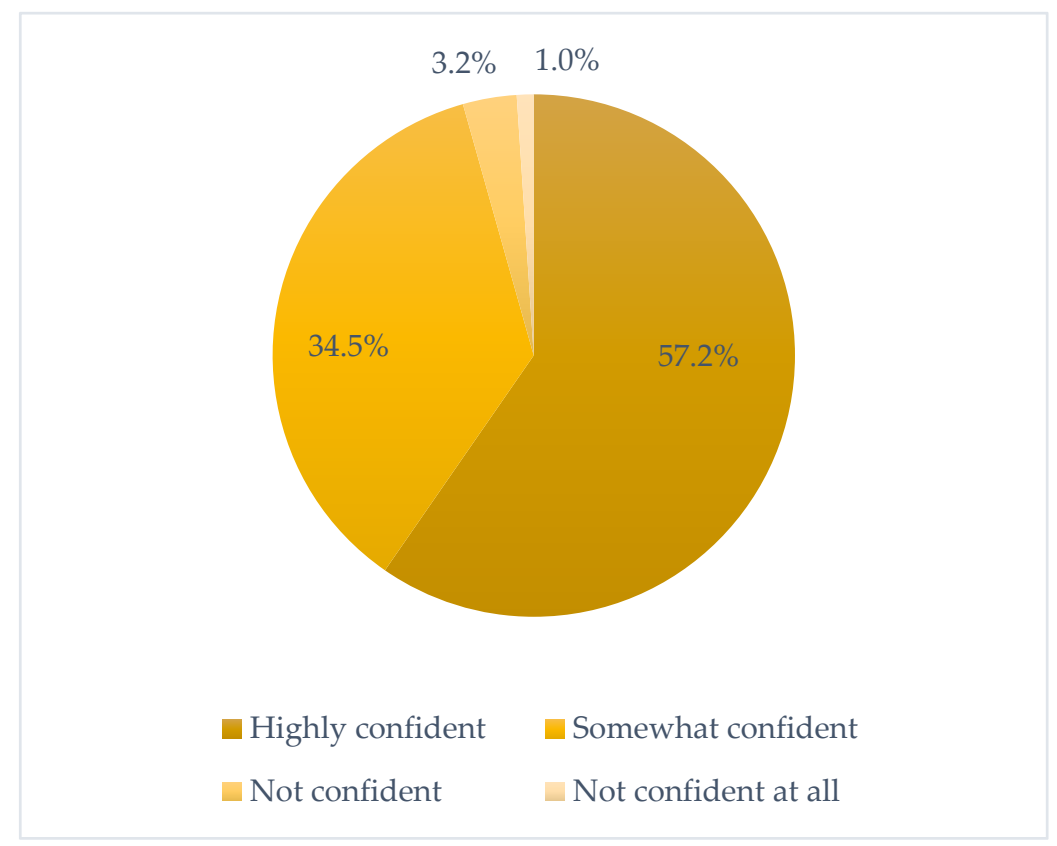

Figure 1. Perception of food security and confidence in the provision of food. Participants were asked how confident are you in the country's provision of food to meet consumer needs?

\section{Discussion and Conclusions}

This study investigated the impact of the COVID-19 pandemic on food purchasing behaviors, eating behaviors, and perception of food safety among residents in Kuwait. Globally, the COVID-19 pandemic has affected behaviors related to buying food, meal preparation, and eating habits [21-23]. These changes have been attributed to the closures of schools, restaurants, businesses, and lockdowns that restricted socializing and outdoor activities. In the current study, it was evident that the pandemic had an immediate impact on food dynamics in Kuwait. The study found that the majority (91.7\%) were 'confident' or 'somewhat confident' that the provision of food (food supply) and safety of food available met their needs. These findings could be explained by the nation's confidence in the governments' immediate response to the pandemic and the implementation of robust public health measures to control the spread of the virus. Moreover, because the government provides food subsidies, it may have provided the Kuwaiti nationals a sense of security. Nevertheless, similar to other studies [26,27], the current study found that $74.1 \%$ changed their food purchasing behaviors during this unprecedented period. Largely, these were in line with international and national public health guidance to prevent and/or control the spread of the virus. However, it is important to note that these changes were mostly due to the growing fear related to contracting the virus $(71.2 \%)$, which led consumers to become more cautious and shift their purchasing behaviors from instore to online. The study found that $30 \%$ switched to online food delivery services to avoid visiting the supermarkets, and $44 \%$ chose to visit supermarkets less often, which was compensated by stockpiling or bulk-buying. However, although consumers reported that they were confident in the available food supply, the study found that $27.6 \%$ bought more food than usual, in particular non-perishable foods (e.g., beans, rice, lentils, and legumes), frozen foods (e.g., ready meals, fruits, and vegetables etc.), and canned foods (e.g., chickpeas foul and vegetables). Hence, these findings suggest that consumers were bulk-buying or panic-buying, which is similar to what was observed in other countries that also reported changes in food purchasing behaviors and stockpiling [24-26,28]. Furthermore, with respect to gender differences, the study found that more women than men changed their food purchasing behaviors. Women were found to bulk-buy to ensure that non-perishable foods such as ready-made frozen foods and canned foods. These findings seem to be unique to Kuwait, as other studies that observed changes in grocery shopping found 
no differences between genders [33-35,37]. However, these gender differences could be explained by cultural norms in Kuwait, where women feel more responsible that all family members are well fed.

Additionally, several differences between Kuwaitis and non-Kuwaitis were noted in the study. In particular, non-Kuwaitis were found to change their food purchasing habits more than Kuwaiti nationals. Non-Kuwaitis were found to purchase more food during each shopping trip, reduce their time shopping, and share a concern of not having enough money, while Kuwaiti nationals were found to shop more frequently and preferred online shopping. These findings are comparable to a study in Qatar that reported differences between Qataris and non-Qataris in relation to their buying behaviors. For example, non-Qataris were found to bulk-buy more than Qataris, whereas Qatari nationals used contactless online delivery services compared to non-Qataris [40]. These comparable findings could be related to governmental subsidies and benefits provided to citizens in Gulf Cooperation Council countries, which in turn provide a sense of comfort and reassurance during the pandemic.

In agreement with a study by Ben Hassen et al. [40] in Qatar, and another study by Gornicka et al. [45] in Poland which demonstrated that consumers opted for a healthier diet, the findings of the current study also found that consumers were choosing healthier foods, such as fruits and vegetables (68.8\%), less confectionaries, and savory snacks $(15.5 \%)$, and chose to drink water instead of other beverages. However, the study also found that almost half (43.8\%) of the study participants reported that their food consumption remained the same, whereas a third reported that their food consumption increased (33.7\%), and $18.4 \%$ reported that their food consumption decreased. These changes in food consumption were similar to previous studies $[34,35]$, which could be explained by the growing uncertainty and continuous anxiety that could drive individuals to choose more comfort foods that are likely to be higher in fat and sugar [34-36,46,47]. For example, studies in Kuwait, the United Arab Emirates, France, Italy, and United States all reported an increase in the consumption of energy-dense foods (high-calorie foods rich in sugar and fat) which was also coupled with weight gain during periods of quarantine and lockdowns [47-50]. However, it is important to note that food consumption investigated in this study is subjective and does not reflect actual food consumption, therefore changes in eating behaviors and food consumption need to be interpreted with caution, and future studies may benefit from collecting objective dietary data using validated dietary assessment tools (e.g., food diaries or food frequency questionnaires). Moreover, although many studies observed weight gain due to the excessive consumption of energy-dense foods $[36,46,47,50]$, the present study did not collect any anthropometric data; therefore, it is not possible to ascertain whether changes in food consumption influenced body weight. Nevertheless, several studies carried out during the COVID-19 pandemic found that body weight, food consumption, and physical activity habits changed [46-50]. For example, in Kuwait, although Husain and Ashkanani [47] reported a decrease in the consumption of fast food, their study also found a reduction in physical activity, an increase in day-time sleep and late-night snacking. Ismail et al. [48] in the United Arab Emirates found that 31\% gained weight, and $72.2 \%$ did not drink enough water. Moreover, they observed a shift towards unhealthy dietary patterns, low physical activity, and an increase in screen time. Likewise, Pellegrini et al. [51] found that, after 1 month of an imposed lockdown in Northern Italy, obese individuals self-reported an increase in body weight, a decrease in physical exercise, and an increase in the consumption of snacks, unhealthy foods, breakfast cereals, and sweets [51]. These findings highlight the need for nutrition education initiatives to educate individuals and promote a healthier lifestyle during and after this pandemic.

Gender differences were noted for food consumption. More men reported that their food consumption decreased compared to women, and more men reported that less food available at home was a contributing factor. Other factors may also be responsible, such as undereating due to stress and changes in men's usual social dynamics. For example, in Kuwait, an important feature of men's social life is a daily or weekly gathering that takes 
place in a diwaniya, which is a reception area commonly adjacent to the host's home. These social gatherings bring together colleagues, friends, and family members to socialize and share meals. Therefore, suspension of all social gatherings in Kuwait may have influenced men's usual eating behaviors and overall dietary habits. Nonetheless, due to the lack of objective dietary assessment, it is not possible to understand the reason for the change in food consumption and distinguish the type of food that was not available at home.

With respect to the type of food, women were found to eat more healthy food than usual, whereas men reported consuming more rice-based dishes, coffee, and tea. This could be due to the fact that women intentionally focused more on their dietary habits and opted for healthier home-prepared meals. Similar to other studies $[36,40,48]$, the closures of restaurants and fast-food outlets facilitated more home cooking, and people were focused on cooking more traditional Kuwaiti meals (e.g., rice-based dishes and stews made from chicken, lamb, and fish). The study also found that non-Kuwaitis purchased less from restaurants, which could be due to the fact that food delivery may be more expensive than home-cooked meals. However, since supermarkets remained open, Kuwaitis were found to consume more baked goods, pastries, and juices. These findings are similar to previous studies that also found that individuals may comfort eat while they spend more time indoors $[40,48]$.

During the coronavirus pandemic, there was growing concern on the transmission of the virus through packaging (cardboard, plastic, metal) and surfaces; however, despite the weak available evidence [7,40,52-55], many consumers vigilantly followed public health measures to prevent contracting the virus from packages or shared surfaces. Similar to findings published by the International Food Information Council $(42,52,53)$, the current study also found that consumers followed handwashing guidance, opted for contactless payment methods (e.g., using credit cards instead of cash), wore gloves, used online delivery services, and/or avoided supermarkets and food shops during busing hours. These findings could be explained by the effective strategies and guidance put in place by MOCI to facilitate easy and safe access to supermarkets. Moreover, as a precautionary measure to control the spread of the virus in Kuwait, public health authorities ensured that all supermarkets maintained a high-level sanitation by continuously sanitizing trolleys, providing disposable plastic handle covers, installing hand sanitizing units, and offering face masks and gloves for consumers [52]. The Public Authority for Food and Nutrition (PAFN) in Kuwait also ensured that all food handlers in supermarkets and restaurants wore masks and gloves and followed public health guidelines measures to control the spread of the virus. Consequently, it is not surprising that the present study found that participants were reassured when food handlers in supermarkets and food retailers wore wear masks, cleaned surfaces regularly, and maintained social distancing measures. Additionally, despite the lack of evidence available to support the transmission of the virus from handling food prepared in restaurants or contracting the virus from consuming food [7,54], the present study demonstrated a clear discrepancy with respect to consumers perception of food safety from supermarkets and restaurants. For example, while $85 \%$ reported that they 'trusted' or 'somewhat trusted' the safety of food, around $60 \%$ did 'not trust' or 'did not trust at all' food purchased from restaurants/food delivery services. These findings are similar to another study that found that, due to food safety concerns, many consumers in Qatar chose to consume locally produced foods and prepare more food at home [40].

There are several limitations that need to be noted in the present study. First, the study is cross-sectional in nature and, thus, the findings are intermittent, subjective, and do not reflect the changes during the 6-month period of partial and full lockdown in Kuwait. Furthermore, the cross-sectional nature of this study does not allow us to confer causation, and hence the findings of this study need to be interpreted with caution. Further investigation of longitudinal changes would possibly provide insightful information, particularly if these investigated behaviors changed as the government eased restrictions. Secondly, Kuwaiti households are collective in nature and include many members (e.g., grandparents and extend family members), therefore it is unclear whether the respondent participating 
in the study is the sole person purchasing food for the household. Hence, it is not possible to differentiate whether these changes are individual or household changes. Third, the questionnaire was only disseminated in the Arabic language, therefore findings of this study are not representative of the whole population in Kuwait that includes more than 120 nationalities, some of which are non-Arabic speakers. Future studies should include both English- and Arabic-speaking residents in Kuwait. Fourth, the use of snowball sampling and WhatsApp to disseminate the questionnaire is fraught with limitations due to sampling bias, such that the population is not clearly defined as with random sampling, and therefore it is not possible to know who receives and completes the survey. However, in consideration of the social distancing guidance and restrictions, this method of data collection was feasible and in line with public health measures. Fifth, the sample size of the study was only 841, and therefore findings cannot be generalizable. Future research should focus on recruiting a larger representative sample to improve generalizability of the findings to the whole population. Sixth, findings categorized by gender and nationality should be interpreted with caution, since the majority of study participants were female and Kuwaiti residents. Hence, this limited the generalizability of findings to the general population in Kuwait. Lastly, several important socio-demographic factors were not included in the study questionnaire (e.g., social class, family income, educational level) which would have provided valuable information on differences that may exist between different segments of the population.

In conclusion, in light of the growing uncertainty during the COVID-19 pandemic, the findings of the present study demonstrated a change in food purchasing behaviors, eating behaviors, food consumption, and overall perception of food safety. Gender and nationality differences identified may better inform public health authorities and initiatives in Kuwait to tailor future resources and services to meet their individual needs. Collectively, findings of the study are unique and informative, and to our knowledge this is the first and only study that investigated the immediate impact of COVID-19 pandemic on the food purchasing, food consumption, and food safety perception in Kuwait. Future longitudinal studies may provide greater insight on the long-term influence of the pandemic on consumers food dynamics, and whether they will return to how they were before the pandemic.

Supplementary Materials: The following are available online at https: / www.mdpi.com/article / 10.3390/su13168987/s1, Figures S1-1 to S1-3: Food purchasing, Figures S2-1 to S2-4: Food Safety, Figures S3-1 to S3-6: Food consumption.

Author Contributions: Conceptualization, E.A., N.A., F.A.; methodology, D.A., E.A., F.A.; formal analysis, D.A., S.D.; writing-original draft preparation, D.A., E.A., N.A., F.A.; writing-review and editing, D.A., E.A., N.A., F.A. All authors have read and agreed to the published version of the manuscript.

Funding: This research received no external funding.

Institutional Review Board Statement: The study was conducted according to the guidelines of the Declaration of Helsinki and approved by the Ethics Committee of the Ministry of Health, Kuwait (protocol code 1590/2020, 12 July 2020).

Informed Consent Statement: Informed consent was obtained from all subjects involved in the study.

Conflicts of Interest: The authors declare no conflict of interest.

\section{References}

1. Andersen, K.G.; Rambaut, A.; Lipkin, W.I.; Holmes, E.C.; Garry, R.F. The proximal origin of SARS-CoV-2. Nat. Med. 2020, 26, 450-452. [CrossRef]

2. Shi, Y.; Wang, G.; Cai, X.-P.; Deng, J.-W.; Zheng, L.; Zhu, H.-H.; Zheng, M.; Yang, B.; Chen, Z. An overview of COVID-19. J. Zhejiang Univ. Sci. B 2020, 21, 343-360. [CrossRef]

3. WHO. WHO Director-General's Opening Remarks at the Media Briefing on COVID-19, 11 March 2020. Available online: https:/ / www.who.int/dg/speeches / detail/who-director-general-s-opening-remarks-at-the-mediabriefing-on-covid-19---11march-2020 (accessed on 20 October 2020). 
4. Huang, C.; Wang, Y.; Li, X.; Ren, L.; Zhao, J.; Hu, Y.; Zhang, L.; Fan, G.; Xu, J.; Gu, X.; et al. Clinical features of patients infected with 2019 novel coronavirus in Wuhan, China. Lancet 2020, 395, 497-506. [CrossRef]

5. Chen, N.; Zhou, M.; Dong, X.; Qu, J.; Gong, F.; Han, Y.; Qiu, Y.; Wang, J.; Liu, Y.; Wei, Y.; et al. Epidemiological and clinical characteristics of 99 cases of 2019 novel coronavirus pneumonia in Wuhan, China: A descriptive study. Lancet 2020, 15, 507-513. [CrossRef]

6. WHO. WHO Coronavirus (COVID-19) Advice for the Public. Available online: https://www.who.int/emergencies/diseases/ novel-coronavirus-2019/advice-for-public (accessed on 20 October 2020).

7. WHO. COVID-19 Question and Answer, Food Safety. Available online: https://www.who.int/emergencies/diseases/ novel-coronavirus-2019/question-and-answers-hub/q-a-detail/food-safety-and-nutrition\#: \{\}:text=delivery (accessed on 5 October 2020).

8. Circular of the Civil Service Bureau No.7 2020, Kuwait. Available online: https://www.kuwaitculture.com/civil-servicecommission/civil-service-rules-and-regulations (accessed on 10 September 2020).

9. COVID-19 (Coronavirus): Panic Buying and Its Impact on Global Health Supply Chains; World Bank Blogs. 2020. Available online: https:/ / blogs.worldbank.org/health/covid-19-coronavirus-panic-buying-and-its-impact-global-health-supply-chains (accessed on 20 May 2020).

10. Mao, F. Coronavirus Panic: Why Are People Stockpiling Toilet Paper? 2020. Available online: https://www.bbc.com/news / world-australia-51731422 (accessed on 10 May 2020).

11. Sterman, J.D.; Dogan, G. I'm not hoarding, I'm just stocking up before the hoarders get here: Behavioral causes of phantom ordering in supply chains. J. Operat. Manag. 2015, 39, 6-22. [CrossRef]

12. Ministry of Commerce and Industry Kuwait. Available online: www.moci.gov.kw (accessed on 5 October 2020).

13. Martin-Neuninger, R.; Ruby, M.B. What does food retail research tell us about the implications of Coronavirus (COVID-19) for grocery purchasing habits? Front. Psychol. 2020. [CrossRef]

14. Koh, D. COVID-19 lockdowns throughout the world. Occup. Med. 2020, 70, 322. [CrossRef]

15. Wilder-Smith, A.; Freedman, D. Isolation, quarantine, social distancing and community containment: Pivotal role for old-style public health measures in the novel coronavirus (2019-nCoV) outbreak. J. Travel Med. 2020, 27, 20. [CrossRef] [PubMed]

16. Food and Agriculture Organization (FAO). COVID-19 and its Impact on Food Security in the Near East and North Africa: How to respond? 2020. Available online: http:/ / www.fao.org/3/ca8778en/CA8778EN.pdf (accessed on 5 October 2020).

17. Erokhin, V.; Gao, T. Impacts of COVID-19 on trade and economic aspects of food security: Evidence from 45 developing countries. Int. J. Environ. Res. Public Health 2020, 17, 5775. [CrossRef]

18. Béné, C. Resilience of local food systems and links to food security-A review of some important concepts in the context of COVID-19 and other shocks. Food Secur. 2020, 11, 1-8. [CrossRef]

19. OECD. COVID-19 and the Food and Agriculture Sector: Issues and Policy Responses; OECD: Paris, France, 2020.

20. HLPE. Interim Issues Paper on the Impact of COVID-19 on Food Security and Nutrition (FSN) by the High-Level Panel of Experts on Food Security and Nutrition (HLPE); FAO: Rome, Italy, 2020.

21. United Nations. Policy Brief: The Impact of COVID-19 on Food Security and Nutrition; United Nations: New York, NY, USA, 2020.

22. Recchia, L.; Cappelli, A.; Cini, E.; Garbati Pegna, F.; Boncinelli, P. Environmental Sustainability of Pasta Production Chains: An Integrated Approach for Comparing Local and Global Chains. Resources 2019, 8, 56. [CrossRef]

23. FAO. Food Outlook—Biannual Report on Global Food Markets; FAO: Rome, Italy, 2020.

24. Beard-Knowland, T. The Impact of Covid-19 on How We Eat. 2020. Available online: https://www.ipsos.com/sites/default/ files/ct/publication/documents/2020-05/impact_of_covid-19_on_how_we_eat_ipsos_sia.pdf (accessed on 20 July 2021).

25. Baker, S.; Meyer, S.; Pagel, M.; Yannelis, C. How Does Household Spending Respond to an Epidemic? Consumption during the 2020 COVID-19 Pandemic; NBER Working Papers 26949; National Bureau of Economic Research: Cambridge, MA, USA, 2020; Available online: https: / /ideas.repec.org/p/nbr/nberwo/26949.html (accessed on 20 July 2021).

26. Grasso, S. Consequences of Panic Buying, IFNH. Available online: https://research.reading.ac.uk/ifnh/2020/04/20 / consequences-of-panic-buying/ (accessed on 20 July 2021).

27. Cranfield, J.A.L. Framing consumer food demand responses in a viral pandemic. Can. J. Agric. Econ. Can. Agroecon. 2020, 68, 151-156. [CrossRef]

28. Chen, C.Y.; Lee, L.; Yap, A.J. Control Deprivation Motivates Acquisition of Utilitarian Products. J. Consum. Res. 2017, 43, 1031-1047. [CrossRef]

29. The United Nations System Standing Committee on Nutrition. Food Environments in the COVID-19 Pandemic. Available online: https: / / www.unscn.org/en/news-events / recent-news?idnews=2040 (accessed on 21 July 2021).

30. IPES-Food. COVID-19 and the Crisis in Food Systems: Symptoms, Causes, and Potential Solutions. 2020. Available online: http://www.ipes-food.org/_img/upload/files/COVID-19_CommuniqueEN\%282\%29.pdf (accessed on 21 July 2021).

31. Wang, C.; Pan, R.; Wan, X.; Tan, Y.; Xu, L.; Ho, C.S.; Ho, R.C. Immediate Psychological Responses and Associated Factors during the Initial Stage of the 2019 Coronavirus Disease (COVID-19) Epidemic among the General Population in China. Int. J. Environ. Res. Public Health 2020, 17, 1729. [CrossRef] [PubMed]

32. Evers, C.; Dingemans, A.; Junghans, A.F.; Boevé, A. Feeling bad or feeling good, does emotion affect your consumption of food? A meta-analysis of the experimental evidence. Neurosci. Biobehav. Rev. 2018, 9, 195-208. [CrossRef] 
33. Moynihan, A.B.; van Tilburg, W.A.; Igou, E.R.; Wisman, A.; Donnelly, A.E.; Mulcaire, J.B. Eaten up by boredom: Consuming food to escape awareness of the bored self. Front. Psychol. 2015, 6, 369. [CrossRef]

34. Y1lmaz, C.; Gökmen, V. Neuroactive compounds in foods: Occurrence, mechanism and potential health effects. Food Res. Int. 2020, 128, 108744. [CrossRef] [PubMed]

35. Scarmozzino, F.; Visioli, F. Covid-19 and the Subsequent Lockdown Modified Dietary Habits of Almost Half the Population in an Italian Sample. Foods 2020, 9, 675. [CrossRef] [PubMed]

36. Di Renzo, L.; Gualtieri, P.; Pivari, F.; Soldati, L.; Attinà, A.; Cinelli, G.; Leggeri, C.; Caparello, G.; Barrea, L.; Scerbo, F.; et al. Eating habits and lifestyle changes during COVID-19 lockdown: An Italian survey. J. Transl. Med. 2020, 18, 229. [CrossRef]

37. Ammar, A.A.; Brach, M.; Trabelsi, K.; Chtourou, H.; Boukhris, O.; Masmoudi, L.; Bouaziz, B.; Bentlage, E.; How, D.; Ahmed, M.; et al. Effects of COVID-19 Home Confinement on Eating Behaviour and Physical Activity: Results of the ECLB-COVID19 International Online Survey. Nutrients 2020, 12, 1583. [CrossRef]

38. Jribi, S.; Ben Ismail, H.; Doggui, D.; Debbabi, H. COVID-19 virus outbreak lockdown: What impacts on household food wastage? Environ. Dev. Sustain. 2020, 22, 3939-3955. [CrossRef]

39. The Food Industry Association. U.S. Grocery Shopper Trends: The Impact of COVID-19. 2020. Available online: https: / / www.fmi.org/docs/default-source/webinars/trends-covid-19-webinar.pdf?sfvrsn=307a9677_0 (accessed on 20 July 2021).

40. Ben Hassen, T.; El Bilali, H.; Allahyari, S.M. Impact of COVID-19 on Food Behavior and Consumption in Qatar. Sustainability 2020, 12, 6973. [CrossRef]

41. FAO. QEA: COVID-19 Pandemic-Impact on Food and Agriculture Q1: Will Covid-19 Have Negative Impacts on Global Food Security? FAO: Rome, Italy, 2020.

42. Consumer Survey: COVID-19's Impact on Food Purchasing, Eating Behaviors and Perceptions of Food Safety. 14 April 2020. Available online: https: / foodinsight.org/consumer-survey-a-second-look-at-covid-19s-impact-on-food-purchasing-eatingbehaviors/ (accessed on 25 April 2020).

43. Wild, D.; Grove, A.; Martin, M.; Eremenco, S.; McElroy, S.; Verjee-Lorenz, A.; Erikson, P. Principles of good practice for the translation and cultural adaptation process for patient-reported outcomes (PRO) measures: Report of the ISPOR task force for translation and cultural adaptation. Value Health 2005, 8, 94-104. [CrossRef] [PubMed]

44. Beaton, D.E.; Bombardier, C.; Guillemin, F.; Ferraz, M.B. Guidelines for the process of cross-cultural adaptation of self-report measures. Spine 2000, 25, 3186-3191. [CrossRef] [PubMed]

45. Górnicka, M.; Drywień, M.E.; Zielinska, M.A.; Hamułka, J. Dietary and lifestyle changes during COVID-19 and the subsequent lockdowns among Polish adults: A Cross-sectional online survey PLifeCOVID-19 study. Nutrients 2020, 12, 2324. [CrossRef]

46. Deschasaux-Tanguy, M.; Druesne-Pecollo, N.; Esseddik, Y.; de Edelenyi, F.S.; Allès, B.; Andreeva, V.A.; Baudry, J.; Charreire, H.; Deschamps, V.; Egnell, M.; et al. Diet and physical activity during the COVID-19 lockdown period (March-May 2020): Results from the French NutriNet-Sante cohort study. medRxiv 2020. [CrossRef]

47. Husain, W.; Ashkanani, F. Does COVID-19 Change Dietary Habits and Lifestyle Behaviours in Kuwait? Environ. Health Prev. Med. 2020, 25, 1-13. [CrossRef]

48. Cheikh Ismail, L.; Osaili, T.M.; Mohamad, M.N.; Al Marzouqi, A.; Jarrar, A.H.; Abu Jamous, D.O.; Magriplis, E.; Ali, H.I.; Al Sabbah, H.; Hasan, H.; et al. Eating habits and lifestyle during COVID-19 lockdown in the United Arab Emirates: A cross-sectional study. Nutrients 2020, 12, 3314. [CrossRef]

49. Deschasaux-Tanguy, M.; Druesne-Pecollo, N.; Esseddik, Y.; de Edelenyi, F.S.; Allès, B.; Andreeva, V.A.; Baudry, J.; Charreire, H.; Deschamps, V.; Egnell, M.; et al. Diet and physical activity during the coronavirus disease 2019 (COVID-19) lockdown (MarchMay 2020): Results from the French NutriNet-Santé cohort study. Am. J. Clin. Nutr. 2021, 113, 924-938. [CrossRef]

50. Bhutani, S.; Cooper, J.A. COVID-19 related home confinement in adults: Weight gain risks and opportunities. Obesity 2020, 28, 1576-1577. [CrossRef]

51. Pellegrini, M.; Ponzo, V.; Rosato, R.; Scumaci, E.; Goitre, I.; Benso, A.; Belcastro, S.; Crespi, C.; De Michieli, F.; Ghigo, E.; et al. Changes in weight and nutritional habits in adults with obesity during the "lockdown" period caused by the COVID-19 virus emergency. Nutrients 2020, 12, 2016. [CrossRef] [PubMed]

52. New World. COVID-19 Update. Updates from the New World team About COVID-19 and Our Stores, 2020. Available online: https: / / www.newworld.co.nz/ covid-19 (accessed on 12 August 2020).

53. Countdown. COVID-19 (Coronavirus) Latest Update. 2020. Available online: https://www.countdown.co.nz/communityenvironment/covid-19 (accessed on 15 October 2020).

54. Center of Diseases and Control, Food and COVID-19. Available online: https://www.cdc.gov/coronavirus/2019-ncov/dailylife-coping/food-and-COVID-19.html (accessed on 4 August 2020).

55. Scaraboto, D.; Joubert, A.M.; Gonzalez-Arcos, C. Using lots of plastic packaging during the coronavirus crisis? You're not alone. Conversation 2020, 668, 1077-1093. 